\title{
Wind Field CFD Analysis on the Flat Roof of the Building
}

\author{
Yuanbo Cai ${ }^{1, a}$, Fang Zhao ${ }^{1, b}$ and Shuqin Liu $^{2, c}$ \\ ${ }^{1}$ University of Jinan, Jinan, 250022 \\ 2 Shandong University, Jinan, 250061 \\ a353630276@qq.com, bme_zhaof@ujn.edu.cn, ${ }^{\mathrm{c}} 2310209472 @ q q . o m$
}

Keywords: CFD, Wind field characters, wind turbine installed position, wind direction.

\begin{abstract}
Wind energy has been rapid development as a kind of renewable energy. Now wind energy is becoming more and more attention in the construction environment, roof mounted wind turbine can not only use the limited land resources in the city, but also make full use of the wind around the building. However, compared with wind field of the flat area, wind field around buildings become more complicated and the wind turbulent intensity becomes stronger due to the structure of the obstacles, which directly affect installation location of the building to install wind turbine. This paper used the Computational Fluid Dynamics (CFD) simulations for the purpose of identifying the different distributions of the wind velocity and turbulence intensity above the actual building roof under different wind directions. And then this paper analyzed suitable heights to install wind turbines at the building roof. Results from the analysis show that the building roof wind velocity can increase by more than $40 \%$ after wind flow met the building, but the turbulence intensity become high, which will become lower gradually with the increase of height. Comprehensive wind velocity and turbulence intensity distributions on the building roof, the suitable installation location of wind turbines on the building roof can be choose.
\end{abstract}

\section{Introduction}

Along with the improvement of people environmental protection consciousness, more and more people begin to pay close attention to the development of renewable energy process. Building installed wind turbine to generate electricity can make full use of the wind around the buildings, and can be direct application in the building itself to avoid the loss in the conveying process. Building-integrated wind turbines are defined as the rotor is small and the turbine capacity is less than $2.5 \mathrm{KW}^{[1]}$. It can widely used in the remote areas where the power supply is insufficient because of its low install cost. Meanwhile developing wind energy around the building can not only realize the sustainable development of architecture, also alleviate the pressure of the energy ${ }^{[2]}$.

In this paper, the computational fluid dynamics (CFD) is adopted to simulate the main building roof in Taipei College of Maritime Technology provides, which can was made for the main body of vocational college teaching building. And it can be seen the changes of wind field above building by simulating different wind directions. The wind velocity and turbulence intensity which can change with the different heights at eight selected locations above building roof can determine the appropriate height of wind turbine installation.

\section{Computational fluid dynamics simulation model}

\subsection{Building model}

The building model choosed the main teach-building of Taipei College of Maritime Technology. According to the relevant data and map of Taipei College of Maritime Technology provides by Taiwan Small/Medium Wind Turbine Association, Fig.1(a). Fig.1(b) shown the 3D model of Taipei College of Maritime Technology drown by Gambit. The building model is expressed by cuboid, and there are no windows and other decorations on the buildings. 


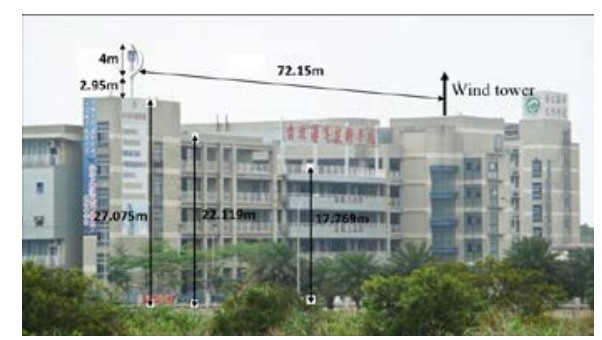

(a) realistic picture

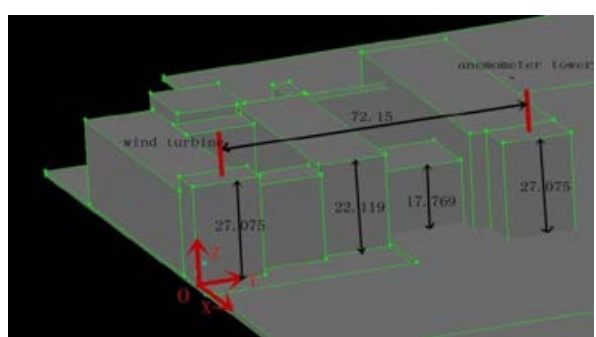

(b) 3D model

Fig.1 the realistic picture and model of Taipei College of Maritime Technology provides

Fig. 2 shows the parameters of the buildings at XOY plane, and the size of flow field around building is $200 \mathrm{~m} \mathrm{X} 200 \mathrm{~m} \mathrm{X} 60 \mathrm{~m}$, and the building located at the middle position of the field. In order to analysis the wind speed changes directly, selecting 8 positions in the building roof to analysis the wind speed changes of building roof. 8 positions are shown by Fig.2, and the coordinate of every position is that: A $(-4,8, Z), B(-4,80, Z), C(-32,8, Z), D(-32,40, Z), E(-32,80, Z), F(-56,8, Z)$, G(-56,40,Z), H(-56,80,Z). The building mesh is shown by Fig.3.

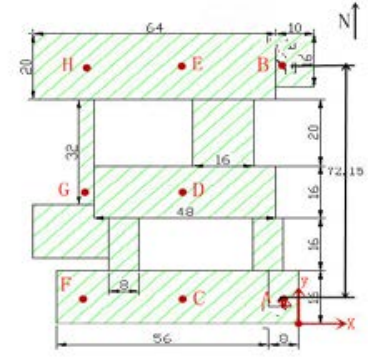

Fig.2 building parameters

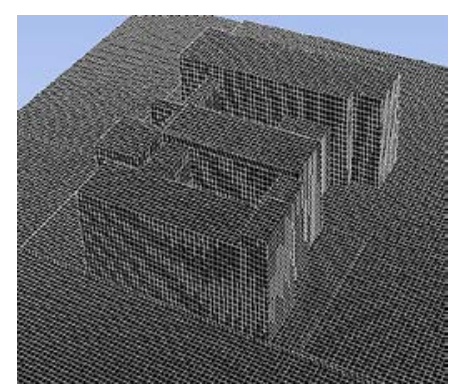

Fig.3 the mesh of building

\subsection{Numerical simulation of turbulence model}

There are some turbulent numerical simulation method included direct numerical simulation (DNS), large eddy simulation (LES), Reynolds average method (RANS) and statistical average method [3-4]. Now Reynolds averaging method is widely used in computational fluid dynamics. The boundary conditions of valley entrance is selected by velocity-inlet boundary, according to the annual average wind speed in this region, the wind velocity in the entrance is designed to $2.1 \mathrm{~m} / \mathrm{s}$; the turbulence intensity is designed to 2\%[5], which can get by Eqs (4)-(6) [6]. Outlet the boundary condition of outlet is used Outflow boundary; the left and right sides of the boundary is designed symmetry boundary except the wind direction is south-east which is used the periodical boundary condition[7]. The building and ground surfaces are used no-slip wall boundary [8-9]. Considering the influence of wind directions to wind velocity on building roof, different wind directions are simulated which are east wind, south wind, west wind, north wind and south-east wind.

$$
\begin{aligned}
& \mathrm{I}=0.16 \operatorname{Re}^{\wedge}(-1 / 8) \\
& \mathrm{Re}=\mathrm{vd} \rho / \eta \\
& \mathrm{L}=4 \mathrm{~A} / \mathrm{P}
\end{aligned}
$$

Where: Re is Reynolds number, $\mathrm{v}$ is average velocity, $\mathrm{d}$ is caliber, $\rho$ is medium density, $\eta$ is medium power coefficient of viscosity, the hydraulic diameter $\mathrm{L}=4 \mathrm{~A} / \mathrm{P}$; A is Inflow surface area, $\mathrm{P}$ is Inflow surface perimeter.

\section{Wind field analysis under different wind direction}

\subsection{Building wind field analysis under south wind}

Fig. 4 shows the velocity contours of each selected location section when wind direction is south wind. The section including position $A$ and $B$ is the plane $X=-4$, the section including position $C, D$ and $E$ is the plane $X=-32$, and the section including position $F, G$ and $H$ is the plane $X=-56$. From velocity contours it can be seen that, when wind met the building, the area above the buildings will form a high wind velocity area. The vertical curve drawn at the selected positions means the need height where the position reached the maximum wind velocity. From Fig.4, the heights of the selected 
positions which reached the highest wind speed at the wind upstream are lower than the positions heights at the wind downstream. But compared with the initial wind speed, $2.1 \mathrm{~m} / \mathrm{s}$, the wind speed above building is also enhanced. The influence of wind field of building courtyard is also very obvious in the picture.

Fig.4(d) showed the velocity distribution graphs of 9selected positions along the height $\mathrm{Z}$ direction. Their starting point in the $\mathrm{z}$ direction is at the actual height in the roof. It can be seen that the wind speed of selected positions reached the highest wind speed when the $\mathrm{Z}$ direction is between $30 \mathrm{~m}$ to $40 \mathrm{~m}$. The wind speed of position A, C, and F are rapidly increased along with the increasing heights, and reached the highest wind speed when height of $Z$ direction is $34 \mathrm{~m}$, and the highest wind speed reached $4 \mathrm{~m} / \mathrm{s}$. other positions can reach the highest wind speed at height $\mathrm{Z}$ is $40 \mathrm{~m}$, and the highest wind speed which can reach $3.5 \mathrm{~m} / \mathrm{s}$ is lower than that of position A,C and F.

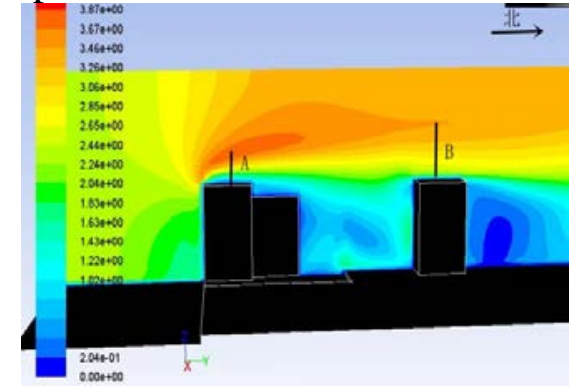

(a) Velocity contours on $\mathrm{X}=-4 \mathrm{~m}$ plane

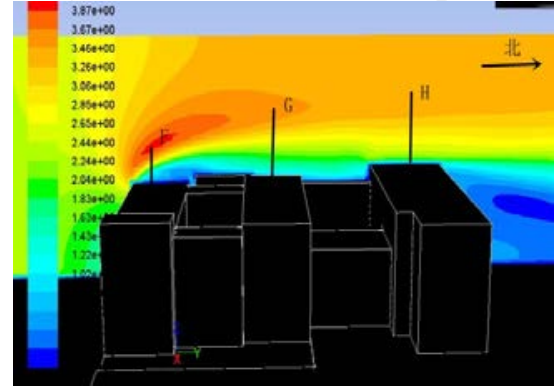

(c) Velocity contours on $\mathrm{X}=-56 \mathrm{~m}$ plane

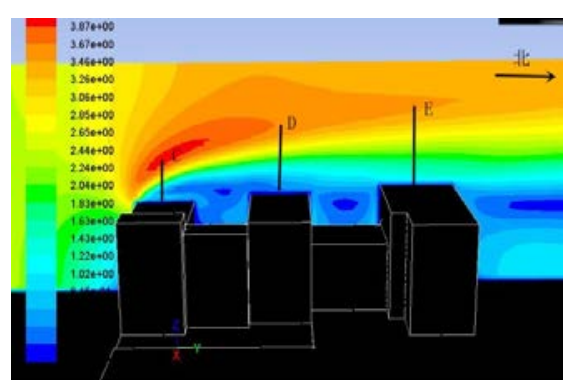

(b) Velocity contours on $\mathrm{X}=-32 \mathrm{~m}$ plane

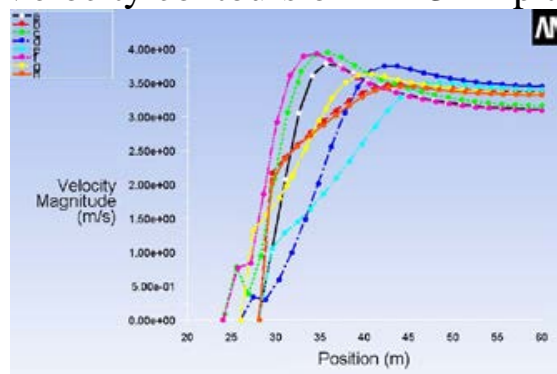

(d) the velocity distribution graphs of 9 selected positions under south wind

Fig.4 velocity contours on $\mathrm{X}$ plane under south wind

\subsection{Building wind field analysis under other wind directions}

Combined with five different wind directions, Table 1 shows the $\mathrm{Z}$ altitude where the highest wind speed of 8 positions reaches;Table 2 shows the highest wind speed of 9 positions and the wind speed rise ratio. From Table 1, the height of every selected position is different under different wind directions, but the average height reaching high wind speed is near $40 \mathrm{~m}$ position. And from Table 2, compared with the initial wind speed,2.1m/s, the rise ratio of highest wind speed is exceed to $45 \%$, and some positions can exceed $60 \%$.

Table 1: The height of each position's highest wind speed under different wind direction (m)

\begin{tabular}{|c|c|c|c|c|c|c|c|c|}
\hline & A & B & C & D & E & F & G & H \\
\hline East wind & 33 & 32 & 39 & 40 & 40 & 41 & 41 & 41 \\
\hline South wind & 34 & 40 & 32 & 40 & 45 & 31 & 37 & 40 \\
\hline West wind & 35 & 45 & 35 & 40 & 40 & 33 & 30 & 35 \\
\hline North wind & 45 & 35 & 47 & 45 & 36 & 45 & 45 & 35 \\
\hline Southeast wind & 32 & 32 & 31 & 43 & 40 & 32 & 30 & 46 \\
\hline
\end{tabular}

Table 2: the highest wind speed and speed rise ratio under different wind direction

\begin{tabular}{|c|c|c|c|c|c|c|c|c|c|c|}
\hline & \multicolumn{2}{|c|}{ East wind } & \multicolumn{2}{c|}{ South wind } & \multicolumn{2}{c|}{ West wind } & \multicolumn{2}{c|}{ North wind } & \multicolumn{2}{c|}{ Southeast wind } \\
\hline winhest & $\begin{array}{c}\text { Rise } \\
\text { ratio }\end{array}$ & $\begin{array}{c}\text { Highest } \\
\text { wind }\end{array}$ & $\begin{array}{c}\text { Rise } \\
\text { ratio }\end{array}$ & $\begin{array}{c}\text { Highest } \\
\text { wind }\end{array}$ & $\begin{array}{c}\text { Rise } \\
\text { ratio }\end{array}$ & $\begin{array}{c}\text { Highest } \\
\text { wind }\end{array}$ & $\begin{array}{c}\text { Rise } \\
\text { ratio }\end{array}$ & $\begin{array}{c}\text { Highest } \\
\text { wind }\end{array}$ & $\begin{array}{c}\text { Rise } \\
\text { ratio }\end{array}$ \\
\hline A & 3.7 & $54 \%$ & 3.7 & $54 \%$ & 3.5 & $45 \%$ & 3 & $43 \%$ & 3.3 & $37.5 \%$ \\
\hline B & 3.5 & $45 \%$ & 3.4 & $42 \%$ & 3.5 & $45 \%$ & 3.5 & $58 \%$ & 4 & $66 \%$ \\
\hline
\end{tabular}




\begin{tabular}{|c|c|c|c|c|c|c|c|c|c|c|}
\hline $\mathrm{C}$ & 3.6 & $50 \%$ & 3.8 & $58 \%$ & 3.6 & $50 \%$ & 3.2 & $52 \%$ & 3.9 & $62.5 \%$ \\
\hline $\mathrm{D}$ & 3.7 & $54 \%$ & 3.7 & $54 \%$ & 3.7 & $54 \%$ & 3.3 & $57 \%$ & 3.5 & $45 \%$ \\
\hline $\mathrm{E}$ & 3.6 & $50 \%$ & 3.4 & $42 \%$ & 3.65 & $52 \%$ & 3.5 & $58 \%$ & 4 & $66 \%$ \\
\hline $\mathrm{F}$ & 3.5 & $45 \%$ & 3.8 & $58 \%$ & 3.8 & $58 \%$ & 3 & $43 \%$ & 4 & $66 \%$ \\
\hline $\mathrm{G}$ & 3.5 & $45 \%$ & 3.5 & $45 \%$ & 3.8 & $58 \%$ & 3.3 & $57 \%$ & 3.8 & $58 \%$ \\
\hline $\mathrm{H}$ & 3.5 & $45 \%$ & 3.4 & $42 \%$ & 3.5 & $45 \%$ & 3.5 & $58 \%$ & 3.7 & $54 \%$ \\
\hline
\end{tabular}

\section{Conclusions}

1) Based on the CFD analysis to the wind field included buildings, the wind speed of building roof and periphery is enhanced largely compared with the initial wind speed. In this paper, the initial wind speed is $2.1 \mathrm{~m} / \mathrm{s}$, the wind speed around building is increased by $40 \%$ at least, and the highest improvement can reach above $90 \%$.

2) Wind velocity and turbulence distribution of different heights on building roof are closely related to the size and shape of the building. Therefore, installations of wind turbines and wind tower should be properly selected the rational location.

3) Due to the different shape and height of buildings, different wind direction will affect the wind field above building roofs. If selecting the wind turbine installed position around the building, it is necessary to understand the local mainstream direction, and to choose the suitable position to install wind turbines according to the mainstream direction.

\section{Acknowledgements}

The investigation presented in this paper was Supported by Natural Science Foundation of Shandong province(ZR2012EEM031). IEA Wind Task 27 .

\section{References}

[1] Peacock AD, Jenkins D, Ahadzi M, Berry A, Turan S. Wind Energy and Buildings 2008;40:p1324-1333.

[2]Xu Yang, Wind energy effective utilization simulation research in the built environment [D]. Jinan: Shandong Jianzhu University, 2012. In Chinese.

[3] Lu L, Ka YI. Investigation on the feasibility and enhancement methods of windpower utilization in high-rise buildings of Hong Kong. Renewable and Sustainable Energy Reviews 2009;13(2):450-461.

[4] Ledo L, Kosasih PB, Cooper P. Roof mounting site analysis for micro-wind turbines. Renewable Energy 2011;36:1379-1391.

[5] Rafailidis S. Influence of building areal density and roof shape on the wind characteristics above a town. Boundary-Layer Meteorology 1997;85:255-271.

[6] Dutton AG, Halliday JA, Blanch MJ. The feasibility of building mounted/integrated wind turbines (BUWTs): achieving their potential for carbon emission reductions. Energy Research Unit, Rutherford Appleton Laboratory, Science \& Technology Facilities Council; 2005.

[7] Islam Abohela, Neveen Hamza, Steven Dudek. Effect of roof shape, wind direction, building height and urban configuration on the energy yield and positioning of roof mounted wind turbines. Renewable Energy;2013;50;1106-1118.

[8] Yuan Xingfei, Zhang Yu, Wind power utilization efficiency on roof of rectangular buildings [J]. civil, architectural and Environmental Engineering, 2012,24(3): 117-123 In Chinese.

[9] Zhang Yu, Wind-energy efficiency study and structural analysis of building integrated/ mounted wind turbines. In Chinese. 